\title{
Possibilidades de Inovação em Educação a Distância: Blogs Educativos como Recurso Didático
}

\author{
Eloiza da Silva Gomes de Oliveira*1, Caio Abitbol Carvalho², Fabiana Triani \\ Barbosa da Silva ${ }^{3}$, Raphael Silberman Dereczynski ${ }^{4}$
}

\footnotetext{
1 Professora Doutora, Instituto Multidisciplinar de Formação Humana com Tecnologias, Universidade do Estado do Rio de Janeiro (UERJ), Brasil. eloizagomes@hotmail.com

2 Bolsista de Iniciação Científica, Faculdade de Educação, Universidade do Estado do Rio de Janeiro (UERJ), Brasil. caioacarvalho@hotmail.com

3 Bolsista de Iniciação Científica do CNPq, Faculdade de Educação, Universidade do Estado do Rio de Janeiro (UERJ), Brasil. trianifabiana@gmail.com

${ }^{4}$ Bolsista de Iniciação Científica, Faculdade de Educação, Universidade do Estado do Rio de Janeiro (UERJ), Brasil. raphaeldere@hotmail.com
}

\section{Resumo}

A internet tornou-se a principal ferramenta de interação entre os jovens, principalmente através das redes sociais. O acesso a notícias, lazer e até mesmo à linguagem estão mudando. É necessário, então, buscar novas formas de ensinar. Uma pesquisa foi realizada na disciplina eletiva oferecida ao curso de graduação em Pedagogia presencial da Faculdade de Educação da UERJ, com o objetivo de verificar a aprendizagem e interação de alunos utilizando um blog educativo. Acompanhamos as aulas presenciais e as postagens feitas no blog e elaboramos um instrumento aplicado ao final do curso. Analisamos 27 questionários, onde itens como "uso do blog como recurso didático" e o conteúdo do mesmo alcançaram alta pontuação. O sucesso da disciplina mostra que a educação mediada por tecnologias foi bem recebida. Iniciamos ajustes das aulas produzidas, transformando-as em objetos de aprendizagem, para a adaptação da disciplina a ambiente virtual de aprendizagem (AVA), cuja utilização oferecerá uma multiplicidade de instrumentos de investigação pertencentes à própria "plataforma".

Palavras-chave: Blog educativo; Aprendizagem com mediação tecnológica; Tecnologia de informação e comunicação. 


\title{
Innovation Possibilities in Distance Education: Educational Blogs as a Teaching Resource
}

\begin{abstract}
The internet has become the primary tool for interaction among young people, especially through social networks. Access to news, entertainment and even language are changing. Therefore is necessary to seek new ways of teaching. A survey was conducted in a course of teacher training of a Brazilian university to verify the learning and interaction of students using an educational blog. In addition to monitoring the regular classrooms and blog posts we prepared a questionnaire at the end of the course. We analyzed 27 questionnaires, where items such as "use the blog as a teaching resource" averaged 3.95 and all items related to the content of the blog reached over 4.14 average (in the maximum of 5.0 points). We still need to develop approaches of distance education further, but with the success of the discipline and the good feedback from students, EAD is being well received by them. We initiated adjustments of the produced classes, turning them into learning objects, to adapt the course to a virtual learning management system (Moodle), which will offer a variety of research tools belonging to own "platform".
\end{abstract}

Keywords: Educational blog; Learning with technological mediation; Information and communication technology. 


\section{Jovens e tecnologias... novos processos de interação e comunicação}

Vivemos o tempo da comunicação mediada pelas tecnologias de informação e comunicação, especialmente com a utilização da internet. Síncrona (em tempo real) ou assíncrona (postando mensagens que podem ser acessadas depois), essa forma de comunicação afetou de tal forma a linguagem que criou o que Bagno (1999, p. 23) chamou de "novo gênero textual", mais atual que qualquer outro na língua portuguesa e amplamente disseminado entre os jovens. O autor detecta um retorno às formas ideográficas, primitivamente, compostas apenas por sinais. Esse fenômeno vem impactando fortemente a educação, em que a primazia da norma culta da língua e o preconceito contra as variantes linguísticas ainda impera.

Outra questão recente é o da conexão às redes sociais. Essa forma de interação superou outras, que foram preponderantes em séculos e décadas anteriores: as cartas, o telefone e até mesmo mais recentemente os e-mails e chats. Conjugadas às tecnologias móveis dos celulares e aos diversos aplicativos hoje disponíveis, não é de estranhar que jovens e tecnologias sejam inseparáveis.

A abordagem de redes feita por Castells, ao falar do paradigma da informação, é muito pertinente. Para o autor, as redes, que dão forma atualmente às relações sociais, "são instrumentos apropriados para: a economia capitalista baseada na inovação, globalização e concentração descentralizada; para o trabalho, trabalhadores e empresas voltadas para a flexibilidade e adaptabilidade; para uma cultura de desconstrução e reconstrução contínuas" (Castells, 2002, p. 498).

Tudo isso configura novas sociabilidades e relações com o espaço e a temporalidade, o acesso a novos mecanismos de interação e a construção de uma identidade própria e múltipla, além da nova configuração de grupos ou tribos. Castells, na mesma obra, aponta a existência de uma cultura da virtualidade real e o surgimento das redes interativas. $O$ aspecto multimídia das novas tecnologias transforma as experiências humanas de percepção e criação simbólica e traz novo caráter ao sistema de comunicação que, diversificado, multimodal e versátil, "é capaz de abarcar e integrar todas as formas de expressão, bem como a diversidade de interesses, valores e imaginações, inclusive a expressão de conflitos sociais" (Castells, 2002, p.461). 
Até mesmo os movimentos sociais são afetados por essa nova cultura individualizante que valoriza os aspectos da vida íntima das pessoas, suas escolhas e sentimentos e acaba por desestimular a participação cívica e as relações sociais impessoais em espaços coletivos.

Apresentadas essas questões mais gerais vamos agora abordar o impacto desse processo interacional / cultural sobre os jovens.

Afastando-nos da polêmica conceitual sobre as formas de designar esses jovens - "Geração Internet" (N-Generation), "Geração Digital" (D-Generation), "Geração do Milênio" (Millenials), "Geração Z" - ou outras, bastante discutidas, como nativos digitais (Prensky, 2001) e residentes digitais (White \&Le Cornu, 2011), nos interessa o impacto do informacionalismo de que fala Castells (2002) sobre os jovens de hoje e os seus processos cognitivos, sociais, sobre a forma como aprendem e se comunicam.

Diante da controvérsia infindável sobre sociedade da informação ou sociedade do conhecimento, Manuel Castells (2002) afirma que a informação é essencial para a construção do conhecimento. Associada à tecnologia é a propulsora dessa nova sociedade, que ele chama de pós-industrial.

O conhecimento é considerado como "um conjunto de declarações organizadas sobre fatos e ideias, apresentando um julgamento ponderado ou resultado experimental que é transmitido a outros por intermédio de algum meio de comunicação, de alguma forma sistemática" (Castells, 2002, p. 45). O autor forja a expressão informacionalismo, um novo modo de desenvolvimento que privilegia o uso de tecnologia no processamento da informação e no suporte à comunicação simbólica como a principal fonte de produtividade social,

No último volume da trilogia "A Era da Informação", já citada neste texto, o autor conclui:

A promessa da Era da Informação representa o desencadeamento de uma capacidade produtiva jamais vista, mediante o poder da mente. Penso, logo produzo. Com isso, teremos tempo disponível para fazer experiência com a espiritualidade e oportunidade de harmonização com a natureza sem sacrificar o bem-estar material de nossos filhos. O sonho do Iluminismo está ao nosso alcance. Todavia, há enorme defasagem entre nosso excesso de desenvolvimento tecnológico e subdesenvolvimento social. Nossa economia, sociedade e cultura são construídas com base em interesses, valores, instituições e sistemas de 
representação que, em termos gerais, limitam a criatividade coletiva, confiscam a colheita da tecnologia da informação e desviam nossa energia para o confronto autodestrutivo. (p. 437-438).

E, de forma otimista, afirma: "Esta situação não é definitiva. Não há mal eterno na natureza humana".

Pelo enfoque deste texto na formação humana, não podemos deixar de citar o conceito enunciado por Hargreaves (2003, p. 37): "A sociedade do conhecimento é uma sociedade da aprendizagem"

Para o autor, a construção do conhecimento depende da capacidade de os membros de uma sociedade se adaptarem às mudanças continuando a aprender de forma constante, autônoma e uns com os outros. Fabela (2005) fala da sociedade da aprendizagem como uma "cultura aprendente", ambiente no qual todos contribuem para a construção do conhecimento de forma partilhada, contínua e processual, em nível individual e coletivo, e em todos os domínios da sociedade. Para que isso aconteça, no entanto, Fabela (2005) propõe a existência de quatro fatores fundamentais para as situações que envolvem a construção do conhecimento: desafio, significado, integração e, por último, contexto relacional, um ambiente de expressão, partilha e testagem de novas formas de ação e intervenção social. Ouvimos, com frequência, afirmativas depreciativas sobre a aprendizagem e o rendimento acadêmico dos jovens de hoje em relação ao empobrecimento da linguagem; à dispersão da atenção e a perda do foco sobre o objeto a ser aprendido; à impaciência e superficialidade que demonstram nos processo de aprendizagem; ao fato de realizarem muitas tarefas ao mesmo tempo sem alcançar excelência em nenhuma.

Precisamos reconhecer que hoje os jovens aprendem de formas diferentes do que acontecia há pouco tempo. Estão acostumados a obter informações de forma rápida e costumam recorrer primeiramente a fontes digitais e à web antes de procurarem em livros ou na mídia impressa. Interagem com diversas mídias, ao mesmo tempo, pela convivência diária com computadores, videogames, áudio e vídeo digital praticamente desde que nasceram. Mantêm conexão constante com os pares através dos celulares e mensagens instantâneas SMS (os torpedos) ou através dos 
computadores ligados à rede da internet e ferramentas de comunicação (Messenger MSN, Google Talk, WhatsApp, entre outros).

Palfrey e Gasser (2008), autores que concordam em muito com Prensky (2001), falam desses jovens aprendizes como pessoas que possuem uma "persona on-line", levando uma vida on-line e off-line durante todo o dia.

A paixão pela aprendizagem ativa e dinâmica, assim como pelos jogos digitais, é outro traço marcante dessa geração. Veen e Vrakking (2009) afirmam que "eles, os jovens, começam a jogar e buscar soluções para os desafios e, se encontram dificuldades, recorrem a redes humanas para buscar informações que levem à solução".

Podemos falar então de uma aprendizagem fortemente social e cooperativa, com movimentos para compartilhar soluções, dúvidas e descobertas, criando ambiente favorável ao "ensino entre pares e para a emergência de comunidades de aprendizagem" (Oblinger, 2004, p. 3).

Mas será que o sistema educacional e a instituição escolar estão preparados para tais formas de aprendizagem? Aquela visão de que os alunos só podem aprender na escola, com os professores, presencialmente, está ficando ultrapassada. A mediação das tecnologias de informação e comunicação cada vez mais é aplicada à aprendizagem, quer de forma intencional, provocada pelas instituições de ensino, quer espontaneamente, no verdadeiro "milagre" que é a imersão na web.

A mediação intencional acontece, por exemplo, através dos blogs educativos ou edublogs, objeto da pesquisa que realizamos, ou através da utilização de ambientes virtuais de aprendizagem (AVA). São:

(...) sistemas computacionais disponíveis na internet, destinados ao suporte de atividades mediadas pelas tecnologias de informação e comunicação. Com esses sistemas, há a possibilidade de integrar diversas mídias, linguagens e recursos, organizar e disponibilizar informações, promover interações entre pessoas e objetos de conhecimento, elaborar e socializar produções para o alcance de determinados objetivos. Neles são oferecidos basicamente os mesmos recursos existentes na internet (correio eletrônico, fórum, bate-papo, conferência etc), acrescidos da possibilidade de gerenciar as informações de acordo com critérios preestabelecidos de organização dentro das características de cada software (Almeida, 2003, p.331). 
A educação mediada pelas tecnologias digitais se apresenta, dessa forma, como mais interativa buscando, através das ferramentas de interação utilizadas, o ideal de construção coletiva do conhecimento. Existe a possibilidade da participação mais ativa de alunos e professores, além do incentivo à responsabilidade dos mesmos para com o aprendizado. Longe de produzir solidão, pode promover autonomia cognitiva.

O aluno é incentivado a desenvolver autonomia para garantir a condução e efetivação de sua aprendizagem, pois não tem o acompanhamento docente presencial e direto o tempo todo. A construção do material didático, a estruturação dos ambientes virtuais de aprendizagem (AVA), a escolha e utilização das ferramentas de ensino e de aprendizagem, o conhecimento mais aprofundado da turma, avaliações planejadas e continuadas e feedbacks constituem fatores fundamentais ao desenvolvimento da disciplina, ajudando a estimular a atitude autônoma e pesquisadora dos aprendentes.

Tudo isso se constitui em um desafio. Os docentes vivem os dilemas e desafios de um tempo de transição: foram formados na cultura oralista e presencial, acostumados a olhar o outro e interagir no mesmo meio físico de forma síncrona. Segundo Prensky (2001), os professores que atuam na escola e possuem mais de 20 anos são imigrantes no ciberespaço. Ou seja, nasceram em outro meio e aprenderam a construir conhecimento de forma diferente do que essa geração denominada de "nativos" faz.

O docente imigrante digital vive a contradição de ser formado para dominar as formas de produzir e consumir conhecimento utilizando as tecnologias da oratória e de lápis e papel e ser desafiado a organizar situações de aprendizagem utilizando o ferramental digital.

Defendemos a posição de que há necessidade de uma sólida base de pesquisa e desenvolvimento de suporte teórico que leve à profunda reflexão sobre os cursos de formação de educadores e sobre construção práxica que permita ao professor aplicar à prática docente as teorias que aprende na sua formação. Essa discussão transcende a questão do equipamento das escolas, mas aponta para uma revisão dos saberes docentes necessários ao trabalho com os alunos que hoje encontramos. Para Giraffa (1999, p.25), "novas metodologias quem faz é o professor e não o computador, logo, capacitar o professor a entender e aplicar a tecnologia na sua prática docente é fundamental". 
A partir desse novo perfil de aluno, pedagogos desenvolveram um novo meio de aprendizagem. Os conteúdos a serem ensinados ficam disponíveis em blogs. Eles são bastante utilizados na educação de modalidade semipresencial, complementando as aulas ministradas.

O termo é uma corruptela de Weblog (Web - a rede de computadores mundial e Log - tipo de "diário de bordo"). São como sites com temas específicos, e o usuário escolhe o que quer falar. Seja sobre a vida cotidiana, futebol, culinária ou, até mesmo, a divulgação e o comentário de notícias. Os usuários utilizam o texto escrito como base para a comunicação, mas também são permitidas outras mídias como som, imagens, pequenos vídeos. São, portanto, eventos multimídia. O blog é, na realidade, uma página interativa que permite publicações sob o formato de diário, em ordem cronológica, e pode receber comentários dos que o acessam. Pode ser considerado um diário eletrônico ou virtual, divulgado na internet para partilhar informações, ideias, materiais e opiniões.

Almeida (2003, p. 73) diz que os blogs são: "Diários virtuais que proliferam na internet como ferramentas de uma narrativa híbrida (misto de diários, crônicas jornalísticas e correspondências) que representa, simultaneamente, a individualidade e a coletividade, dimensões presentes no imaginário da sociedade pós-moderna".

Segundo Quadros (2005), os blogs, surgidos relativamente por acaso, se multiplicaram a partir de dezembro de 1997, quando o norte-americano John Barger utilizou a palavra Weblog para descrever sites pessoais que permitissem comentários e fossem utilizados com frequência, inicialmente com o hábito de algumas pessoas em se logar à web "anotando, transcrevendo, comentado as suas andanças por territórios virtuais" (Gutierrez, 2004).

Um blog é normalmente organizado por datas e categorias, com o post mais recente sendo exibido em primeiro lugar. Há duas maneiras de existência de um blog. A primeira, e a mais comum, é serem criados e hospedados remotamente no servidor do próprio site de blogs. A segunda forma é a hospedagem em domínio próprio, o que significa que todo o conteúdo do blog será publicado em um domínio de internet.

No âmbito educacional, os blogs oferecem múltiplas atividades aos alunos e professores. É possível estabelecer a interação entre alunos e professor, entre alunos 
da mesma turma, entre turmas da mesma escola e de escolas diversas. Permitem o debate de temas, a veiculação de textos e outros materiais, a expressão de opiniões e, sem dúvida, estimulam a leitura e a produção textual, favorecem, ainda, as práticas colaborativas e as aprendizagens compartilhadas além da autonomia na aprendizagem proposta pelo lema de "aprender a aprender".

Para Baumgartner (2004), os blogs têm potencial intrínseco para afetar positivamente os entornos tradicionais do ensino. Para o autor, o diferencial é a necessidade de modular a sua integração com as instituições educativas, dando confiança à sua utilização como recurso didático. Acrescenta ainda que há a vantagem do caráter exógeno em relação ao espaço educativo, já que são construídos através de hiperlinks na rede e não dependem exclusivamente de um servidor único centralizado.

Segundo Gomes (2005), os blogs com intenções educacionais podem e devem ser:

(...) um pretexto para o desenvolvimento de múltiplas competências. O desenvolvimento de competências associadas à pesquisa e seleção de informação, à produção de texto escrito, ao domínio de diversos serviços e ferramentas da web são algumas das mais valias associadas a muitos projetos de criação de blogs em contextos escolares (p. 313).

As características de interatividade, intertextualidade, multidisciplinaridade e a possibilidade de imediatismo temporal entre o que é postado e as reações e comentários do material atendem aos traços cognitivos e de aprendizagem dos alunos de hoje. A geração jovem, que nasceu e cresceu com as tecnologias digitais presentes em suas vidas é a principal usuária dos blogs e das redes sociais. No âmbito da leitura e da escrita não existe mais aquela estrutura onde o autor escreve e os leitores apenas leem o que está escrito. A leitura é hipertextual e torna-se possível interagir de forma intensa com o que se lê, ampliando inclusive o conceito de autoria.

A aprendizagem se faz em rede a partir da interação e das relações praticadas nos diversos ambientes sociais. A linguagem, capacidade específica do ser humano, é a via de saída das aquisições cognitivas adquiridas ao longo de um processo de aculturação (Vygotsky, 1989). 
Autores como Wenger (1998) consideram que os processos de interação, como os que são oferecidos pelos blogs, possibilitam a criação de "comunidades de prática", caracterizadas pelo compartilhamento de interesses entre seus membros, pelo repertório comum e pelo empreendimento conjunto. Parece difícil acreditar que interagindo virtualmente com o outro, o sujeito poderá ter o mesmo êxito que alguém interagindo fisicamente. No entanto, a interação ocorre do mesmo modo, independente do ambiente onde o sujeito está inserido. Haverá um mediador nesses ambientes, mesmo que ele não esteja presente fisicamente. O espaço virtual possibilita, tanto quanto o ambiente de uma sala de aula, por exemplo, o desenvolvimento do sujeito. As zonas de desenvolvimento proximal dos sujeitos, utilizando o conhecido conceito vygotskyano, serão estimuladas nos ambientes virtuais.

\section{A pesquisa realizada - efeitos do blog como via de apresentação do material didático de um curso}

No desenvolvimento da educação com mediação das tecnologias de informação e comunicação (TIC), conhecida popularmente como educação a distância (EAD), o material didático (MD) constitui-se em uma questão importante, mas não tão estudada quanto é necessário. Não falamos aqui dos estudos oriundos das áreas da interação humano-computador (HIC) ou da tecnologia de informação (TI), conjunto de todas as atividades e soluções providas por recursos computacionais que visam permitir a obtenção, o armazenamento, o acesso, o gerenciamento e o uso das informações (Alecrim, 2011), mas de pesquisas realizadas na área educacional.

Convidamos o leitor a refletir sobre a essencialidade do material didático, elemento-chave na construção do conhecimento, já que efetua a mediação entre os três vértices fundamentais dos processos de ensino e aprendizagem: o professor, o aluno e o conhecimento.

Quando o MD chega ao aluno, um processo bastante diferente do que ocorre no ensino presencial acontece. Por exemplo, o conhecimento apresentado deixa de ser visto como "verdade absoluta", como acontece com o livro didático, pois o aluno dispõe da imensa quantidade de informação, que o universo ciberespacial apresenta, para 
questionar o conteúdo. Preti (2009, p. 3) faz uma dura crítica ao uso do livro didático como se consagrou na nossa educação:

O livro didático contribuiu também para concretizar o projeto capitalista de manter o trabalhador disciplinado, ordenado, sob seu controle, no trabalho fabril. Nesse sentido, o livro didático pode ser percebido como estratégia de disciplinamento, de treinamento à submissão, ao que está predeterminado, pré-escrito. O professor torna-se, assim, um "maestro", isto é, em seu sentido etimológico, um "adestrador", um "amansador". E o aluno, como sujeito passivo, levado a copiar, a reproduzir e a memorizar o que está exposto (imposto) no livro didático.

A construção do conhecimento acontece, portanto, através de uma "transmissão" polifônica em vez de monofônica: o professor detém aquele saber, e a ele cabe, por intermédio do texto, transferi-lo ao aluno.

Finalmente, a interação mediada pelo material didático não acontece apenas em caso da ocorrência de dúvidas, modificando a relação que se estabelece no ensino presencial tradicional, em que o aprendizado se dá na direção professor-aluno, desprezando a riqueza das oportunidades de aprendizagem advindas das relações aluno-aluno e aluno-conteúdo. A riqueza de comunicação e de trocas possibilita um aprendizado muito mais amplo e rico e possibilita ao aluno um acréscimo de consciência crítica capaz de fundamentar escolhas corretas, visando ao desenvolvimento sociocultural e à viabilização da efetiva construção de conhecimento.

Andrade (2003) sintetiza a importância de que falamos, enfatizando:

(...) "produzir um material didático capaz de provocar ou garantir a necessária interatividade do processo ensino-aprendizagem" (p.137), onde o professor passa a exercer o papel de "condutor de um conjunto de atividades que procura levar a construção do conhecimento; daí a necessidade de esse material apresentar-se em uma linguagem dialógica que, na ausência física do professor, possa garantir um certo tom coloquial, reproduzindo mesmo, em alguns casos, uma conversa entre professor e aluno, tornando sua leitura leve e motivadora" (p. 138).

Convictos dos efeitos positivos do uso de blogs educativos, comentados até agora, e sintetizados por Gomes (2005, p. 312-313) ao afirmar que como recurso pedagógico os blogs podem constituir-se em espaço de acesso à informação especializada e de disponibilização de informação por parte do professor e que, como "estratégia pedagógica", podem assumir a forma de portfólio digital, espaço de 
intercâmbio e colaboração, de debate - role playing - e de integração, decidimos utilizá-lo no desenvolvimento da disciplina eletiva semipresencial "Sujeito e Conhecimento na Modernidade - Aprendizagem com mediação das Tecnologias de Informação e Comunicação", oferecida ao curso de Pedagogia da Faculdade de Educação da UERJ no primeiro semestre de 2013.

A disciplina, de 30 horas (dois créditos) foi organizada em cinco encontros presenciais e dez "aulas", ministradas através do blog "Dialogando com Elô" http://dialogandocomelo.blogspot.com.br/. A imagem do blog pode ser vista na Figura 1 , apresentada mais adiante.

\section{Alguns resultados obtidos}

A disciplina desenvolvida através do blog tinha como objetivos: Conhecer e discutir aspectos relevantes da aprendizagem humana. Definir as principais características da aprendizagem com mediação tecnológica. Conceituar essa forma de aprendizagem sob o enfoque de teorias da Psicologia. Aplicar à realidade os conceitos citados; e, como ementa, Introdução: Por que estudar aprendizagem, revisão dos conceitos mais importantes da área. Ausubel e a aprendizagem significativa. Bruner e a apreensão cognitiva da estrutura das áreas de conhecimento. Gagné e a hierarquia de aprendizagem. Bandura e a aprendizagem social. Aplicações dessas teorias à aprendizagem com mediação tecnológica.

A proposta do blog foi aprovada pelos alunos, e tivemos 51 membros participantes além da professora e dos monitores da disciplina. No encerramento da mesma, em julho de 2013, apresentamos um instrumento de avaliação, que nos serviu para a coleta de dados da pesquisa.

Nas duas primeiras partes do questionário, o aluno deveria responder atribuindo conceitos que iam de " $A$ " (péssimo) até " $F$ " (Ótimo) aos itens apresentados. No momento da análise do instrumento, para fins de tabulação, estipulamos um valor para cada conceito ("A" valendo 0,0 e "F" valendo 5,0).

A primeira parte focalizava aspectos gerais da disciplina (ementa, conteúdo, uso do blog como recurso didático, dinâmica das aulas presenciais, estratégias de avaliação utilizadas, relação com a professora e monitoria do curso). 
Apresentamos, no Gráfico 1, a avaliação do uso do blog como recurso didático, resultante dos 42 instrumentos totalmente preenchidos que recebemos.

A segunda parte do instrumento referia-se mais especificamente ao conteúdo da disciplina, e o Gráfico 2 mostra as médias alcançadas pelos itens avaliativos apresentados.

A título de ilustração, acrescentamos quatro comentários adicionais feitos pelos alunos:

Disciplina maravilhosa... É incrível como os textos de Vygotsky parecem prever a tecnologia, ou a tecnologia dá vida às ideias dele... Tratando o professor como mediador da turma, que por sua vez deve trabalhar em uma espécie de colaboração.

Excelente recurso a utilização das aulas virtuais, bem como a condução dos tópicos abordados. Interessante e gerador de autonomia que o aluno do aluno na busca pela construção do próprio conhecimento, fugindo dos meios tradicionais "professor $\mathrm{x}$ aluno $\mathrm{x}$ sala de aula".

Adorei a ideia dos textos no blog, texto simples e de leitura rápida. Gostei muito da disciplina, sendo de grande importância para a minha formação enquanto educadora.

Gostei muito de ter escolhido essa disciplina, achei interessante essa nova forma de EAD e presencial. Vídeos colocados no blog para ajudar a entender a matéria. Muito legal!

\subsection{Figuras e Gráficos}

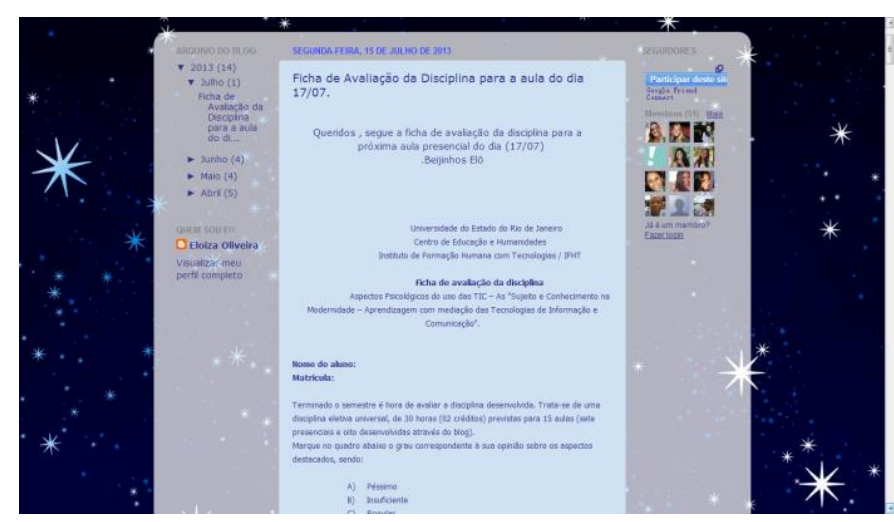

Figura 1. Imagem do blog utilizado 


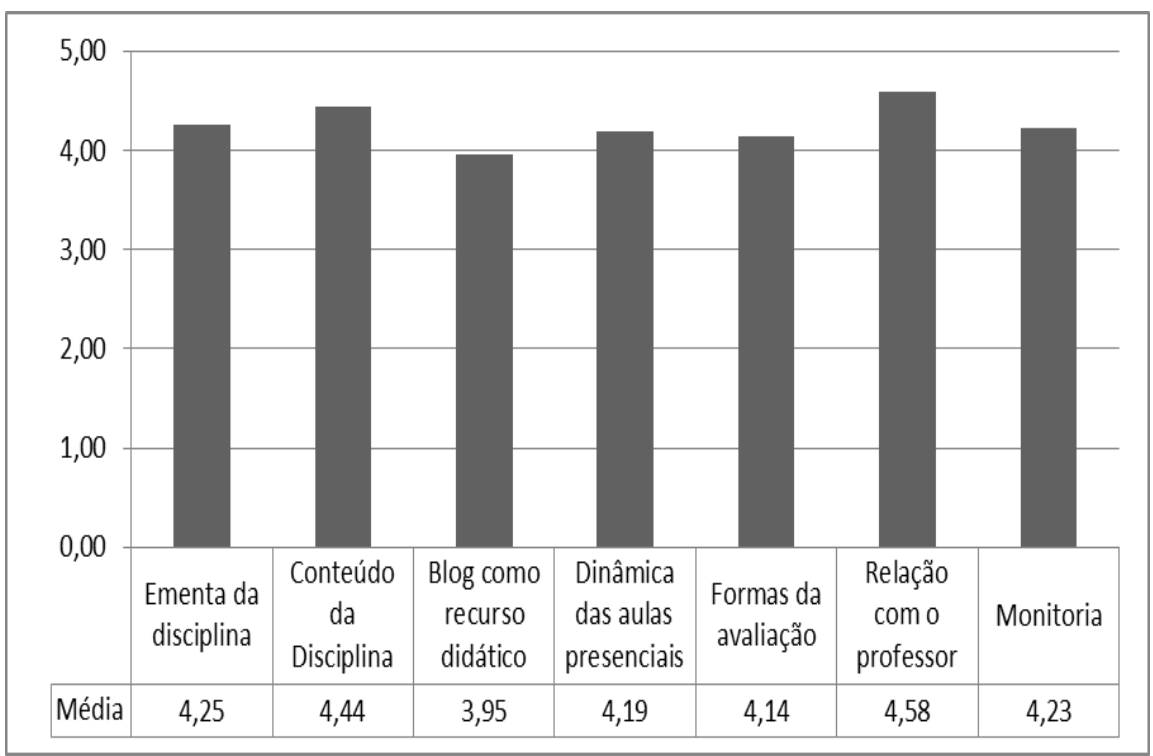

Gráfico 1: Uso do blog como recurso didático

Se for possível: $4^{a}$ linha: vírgula depois de coerência, gradação com $\mathrm{g}$ minúsculo, acentuar coerência na $7^{a}$ linha e no primeiro quadradinho. No $4^{\circ}$ quadradinho, a mesma coisa da $4^{a}$ linha: vírgula depois de coerência, gradação com g minúsculo

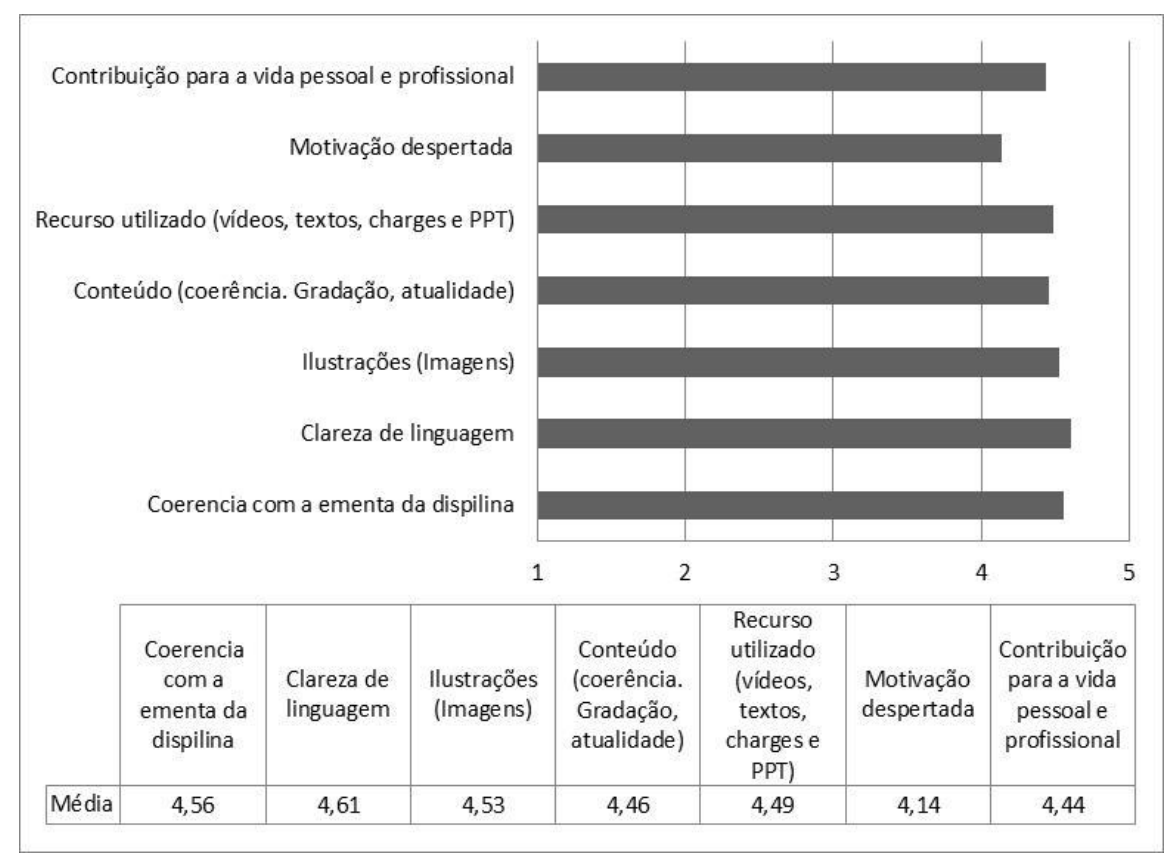

Gráfico 2: Avaliação do conteúdo do blog. 


\section{Considerações finais}

O artigo e a pesquisa que o originou apontam para a necessidade do que podemos chamar de "novas formas de ensinar". Não significa que tudo que a escola faz hoje deve ser descartado, mas que se faz necessária uma inflexão profunda sobre a didática utilizada, sobre as práticas docentes, sobre o cotidiano escolar, sobre os currículos e as estratégias de avaliação da aprendizagem.

O perfil dos alunos, seus estilos cognitivos e preferências motivacionais mudaram muito e rapidamente nos últimos anos, e as mediações oferecidas pelas tecnologias de informação e comunicação podem facilitar bastante esse salto adaptativo que as instituições educacionais precisam realizar. Segundo Kenski (2007, p. 55): "Exposta na tela do computador, a escola virtual se apresenta pela sua imagem. Fluida, mutante, a escola virtual é um ícone de um novo tempo tecnológico do espaço educativo."

Fomos norteados também pelo princípio enunciado por Vygotsky (1989) de que a interação social é a base do desenvolvimento da educação e de que o conhecimento é construído ao longo da história social do homem através de mediações. A rede e as aprendizagens que nela ocorrem são, portanto, uma infindável teia de relações, onde o homem se humaniza mediante as interações estabelecidas.

A busca de práticas colaborativas pela escola, portanto, ajuda a desenvolver estratégias e habilidades gerais de soluções de problemas pelo processo cognitivo implícito na interação e na comunicação.

Constatando a complexidade de tal desafio, desenvolvemos uma pesquisa, cujo principal objetivo era produzir, ofertar e avaliar disciplinas eletivas universais realizadas na modalidade semipresencial e, ao mesmo tempo, verificar a aprendizagem e a interação de alunos utilizando como mediação um blog educativo.

Escolhemos uma disciplina eletiva semipresencial, oferecida ao curso de graduação em Pedagogia no primeiro semestre de 2013, construímos o blog educativo e acompanhamos detalhadamente a sua utilização por ocasião das aulas presenciais e da análise das postagens feitas no blog durante o curso. Elaboramos um questionário que foi aplicado ao final do curso e preenchido na íntegra por 27 alunos. 
Verificamos alto grau de aprovação da disciplina, onde "blog como recurso didático" obteve a média 3,95 e todos os itens relativos ao conteúdo do blog alcançaram mais de 4,14 (no máximo de 5,0 pontos).

Observamos que, após o período inicial em que o acesso ao blog se dava mais para a leitura do material disponibilizado, foi havendo progressivamente uma desinibição, e os alunos começaram a postar dúvidas, comentários, material complementar ao que foi oferecido e a debater algumas questões. Ainda assim, o debate não aconteceu com a mesma intensidade que nos encontros presenciais da disciplina.

Podemos afirmar que as funções de estímulo à produção textual e de compartilhamento de informações realmente ocorreram. Algumas respostas ao questionário destacaram o desenvolvimento da autonomia do aluno e enfatizaram a evolução no "aprender a aprender" e o aumento da facilidade de escrita. Acreditamos, como Soares (2002) define, que:

A tela, como novo espaço de escrita, traz significativas mudanças nas formas de interação entre escritor e leitor, entre escritor e texto, entre leitor e texto até mesmo, mais amplamente, entre o ser humano e o conhecimento. (...) a hipótese é de que essas mudanças tenham consequências sociais, cognitivas e discursivas, e estejam, assim, configurando um letramento digital, isto é, um certo estado ou condição que adquirem os que se apropriam da nova tecnologia digital e exercem práticas de leitura e de escrita na tela, diferente do estado ou condição - do letramento - dos que exercem práticas de leitura e de escrita no papel (p. 151).

Ainda é preciso desenvolver bastante as abordagens da educação com mediação de tecnologias digitais, mas com o sucesso da disciplina e um ótimo feedback dos alunos, percebe-se que esse tipo de mediação está sendo bem recebido por eles.

Como disse uma das alunas:

Definitivamente, os ciberespaços chegaram para colocar um ponto final na educação bancária, onde os alunos são um depósito de conhecimento, e darmos início a uma nova forma de trabalho, onde o professor permite que os alunos construam o seu próprio conhecimento interagindo com o meio e com as atualidades. 
De posse dos resultados da pesquisa desenvolvida, iniciamos a construção da proposta de ajustes do material didático (aulas produzidas), transformando-o em objetos de aprendizagem para a adaptação da disciplina a ser oferecida em ambiente virtual de aprendizagem (AVA). Com a pretensão de utilização do Moodle, poderemos contar também com uma multiplicidade de instrumentos de investigação oferecidos pela própria "plataforma", além de possibilidades de construção de uma disciplina mais dinâmica, com mais recursos didáticos e que estimule maior interação entre os alunos e dos mesmos com o professor.

\section{Referências bibliográficas}

Alecrim, E. (2011). O que é Tecnologia da Informação? Disponível em http://www.infowester.com/ti.php

Almeida, M. E. B. de. (2003). Educação a distância na internet: abordagens e contribuições dos ambientes digitais de aprendizagem. Educação e Pesquisa. V.29 n.2, 327-340. São Paulo.

Almeida, M. E. B. de; Moran, J. M. (2007). Integração das tecnologias na Educação. In: SEED/MEC. Módulo Básico - Gestão Integrada de Mídias/Informática. Brasília.

Andrade, A. F. de (2003). Construindo um ambiente de aprendizagem a distância inspirado na concepção sócio interacionista de Vygotsky. In: Silva, M. (org). Educação online. p. 255-270. São Paulo: Loyola.

Bagno, M. (1999). Preconceito Linguístico: O que é, como se faz. São Paulo: Loyola.

Baumgartner, P. (2004). The Zen Art of Teaching Communication and Interactions in eEducation. Disponível em http://www.ro.feri.unimb.si/razno/icl2004/pdf/baumgartner.pdf

Castells, M. (2002). A Era da Informação: economia, sociedade e cultura; v. 1. A sociedade em rede. Lisboa: Fundação Calouste Gulbenkian.

Castells, M. (2000). A era da Informação: economia, sociedade e cultura; v. 3. Fim de milênio. São Paulo: Paz e Terra.

Fabela, S. (2005). A vida toda para Aprender. In: Portal dos psicólogos. Disponível em http://www.psicologia.pt/artigos/textos/A0321.pdf 
Giraffa, L. M. (1999). Uma Arquitetura de Tutor Utilizando Estados Mentais. Tese (Doutorado em Ciência da Computação) - Instituto de Informática, UFRGS, Porto Alegre.

Gomes, M. J. (2005). Blogs: um recurso e uma estratégia. Anais do VII Simpósio Internacional de Informática Educativa - SIIE0. Leiria, Portugal, 16-18. Disponível em https://repositorium.sdum.uminho.pt/bitstream/1822/4499/1/Blogs-final.pdf

Gutierrez, S. de S., 2004. Mapeando caminhos de autoria e autonomia: a inserção das tecnologias educacionais informatizadas no trabalho de professores que cooperam em comunidades de pesquisadores. Dissertação de Mestrado defendida no Programa de Pós-Graduação em Educação. Porto Alegre: UFRGS. Disponível

em

http://www.lume.ufrgs.br/bitstream/handle/10183/5830/000432196.pdf?sequen $\underline{\mathrm{ce}=1}$

Hargreaves, A. (2003). O Ensino na Sociedade do Conhecimento: a educação na era da insegurança. Porto: Porto Editora.

Kenski, V. M. (2007). Educação e Tecnologias: o novo ritmo da informação. Campinas, Papirus. São Paulo.

Oblinger, D. (2004). The next Generation of Educational Engagement. In: Journal of Interactive Media in Education (8). Special Issue on the Educational Semantic Web. Disponível em http://jime.open.ac.uk/article/view/2004-8-oblinger/198

Palfrey, J. e Gasser, U. (2008). Born Digital - Understanding the First Generation of Digital Natives. New York: Perseus Books.

Prenski, M. Digital Natives, Digital Immigrants (2001). In: On the Horizon, NCB University Press, vol. 9, no. 5.

Preti, O. (2009). Educação a distância: fundamentos e políticas. Cuiabá: EdUFMT.

Quadros, C. I. (2005). A Participação do público no webjornalismo. Revista E-compós, v. 4. Disponível em http://www.compos.org.br/seer/index.php/ecompos/article/viewFile/56/56 
Soares, M. (2002). Novas práticas de leitura e escrita: letramento na cibercultura. Educação e Sociedade. Campinas, v. 23, n.81, 143-160. http://dx.doi.org/10.1590/S0101-73302002008100008

Veen, W. e Vrakking, B. (2009). Homo Zappiens: educando na era digital. Porto Alegre: Artmed.

Vygotsky, L. S. (1989). Pensamento e Linguagem. São Paulo: Martins Fontes.

Wenger, E. (1998). Communities of Practice: Learning, Meaning and Identity. New York: Cambridge University Press.

White, D. S. e Le Cornu, A. (2011). Visitors and residents: Towards a new typology for online engagement. First Monday, 16(9). Disponível em http://firstmonday.org/article/view/3171/3049 